\title{
EXTENSÃO UNIVERSITÁRIA EM PROJETO DE INTERIORES DE UMA BIBLIOTECA ESCOLAR ${ }^{1}$
}

\author{
UNIVERSITY EXTENSION IN INTERIOR DESIGN OF A SCHOOL LIBRARY
}

\author{
Maria Eduarda de Abreu Moraes², Luiza Valle Cielo ${ }^{3}$ e Marina de Alcântara ${ }^{4}$
}

\section{RESUMO}

Este texto tem por objetivo compartilhar as experiências da primeira edição da disciplina de Projeto Comunitário dos Cursos de Arquitetura e Urbanismo e Design da Universidade Franciscana (UFN), de Santa Maria - RS. Ocorrida em 2019, a disciplina tem caráter extensionista e reuniu alunos dos dois cursos de graduação para desenvolver projetos de interiores para alguns ambientes da Escola Básica Estadual Cícero Barreto. A escola pública atende alunos dos anos iniciais até Educação de Jovens e Adultos, ocupando um edifício localizado próximo à UFN. Para fins de exemplificação da metodologia aplicada, traz-se o relato do processo de projeto desenvolvido por um dos grupos de alunos que trabalhou na escola, cujo objeto de proposta era a biblioteca. Das vivências oportunizadas e dos produtos gerados, destaca-se que a aproximação com demandas da comunidade incrementa a formação dos acadêmicos de Arquitetura e Urbanismo e Design, aproximando-os de realidades sociais e econômicas muitas vezes distantes de sua realidade de origem.

Palavras-chave: Comunidade, Disciplina extensionista, Projeto comunitário.

\section{ABSTRACT}

This text aims to share the experiences of the first edition of the Community Project discipline of the Architecture and Urbanism and Design Courses at the Franciscan University (UFN), in Santa Maria - RS. Occurred in 2019, the discipline has an extension character and brought together students from both graduation courses to develop interior designs for some environments of the Cícero Barreto State Basic School. The public school serves students from early years to Youth and Adult Education, occupying a building located close to UFN. For the purpose of exemplifying the applied methodology, we report the project process developed by one of the groups of students who worked at the school, whose object of proposal was the library. From the opportunistic experiences and the generated products, it is noteworthy that the approximation with the community demands increases the formation of the Architecture and Urbanism and Design students, bringing them closer to social and economic realities that are often far from their original realities.

Keywords: Community, Extension discipline, Community project.

1 Trabalho de Iniciação Científica resultante da experiência em uma disciplina de Graduação.

2 E-mail: maria.moraes@ufn.edu.br

3 E-mail: luiza.cielo@ufn.edu.br

4 E-mail: marina.alcantara@ufn.edu.br 


\section{INTRODUÇÃO}

A partir das discussões acerca da curricularização da extensão prevista no Plano Nacional de Educação (BRASIL, 2014) e de sua regulamentação de forma oficial no ano de 2018 pela Resolução $\mathrm{n}^{0} 7 \mathrm{MEC} / \mathrm{CNE} / \mathrm{CES}$ (2018), o Curso de Arquitetura e Urbanismo juntamente do Curso de Design da Universidade Franciscana (UFN) incluíram em suas matrizes curriculares a disciplina de Projeto Comunitário. A oferta da disciplina explora as habilidades técnicas dos acadêmicos no que se refere à sua formação profissional para o desenvolvimento de projetos de interiores, entendendo que essa área de atuação é comum às duas profissões. Paralelo a esse aspecto técnico, a disciplina traz como diferencial a extensão universitária e a sua importância na formação dos acadêmicos.

A extensão universitária é uma oportunidade de os acadêmicos aplicarem o conhecimento técnico assimilado ao longo da graduação em ações sociais e solidárias. Essas têm por objetivo gerar um impacto positivo na sociedade, qualificando o meio em que a universidade se insere ao mesmo tempo em que aproxima os acadêmicos de cenários reais de atuação profissional. Carbonari e Pereira (2007) referem-se à extensão como uma prática de responsabilidade social que vem transformando o ambiente acadêmico rumo a uma nova cultura que impõe reflexões acerca do ensino e da pesquisa nas universidades, de modo que se tornem sensíveis às necessidades sociais, trabalhem no aprofundamento da cidadania e busquem a transformação efetiva da sociedade.

A inclusão da extensão no currículo da graduação com a oferta de Projeto Comunitário entre as disciplinas dos cursos de Arquitetura e Urbanismo e Design, exigiu que fossem repensadas as práticas docentes e o protagonismo dos alunos nos processos de ensino e aprendizagem. A primeira edição da disciplina, no segundo semestre de 2019, teve como objetivo o desenvolvimento de projetos de interiores para a comunidade da Escola Básica Estadual Cícero Barreto, localizada no Bairro Nossa Senhora do Rosário, na região central de Santa Maria. A escola foi definida como público-alvo por tratar-se de uma instituição pública próxima da UFN, viabilizando análises prévias de possíveis demandas pertinentes à escola.

Nesse contexto, o presente artigo tem como objetivo compartilhar o exercício acadêmico de projeto de interiores da biblioteca da Escola Básica Estadual Cícero Barreto para fins de registro do processo e divulgação de resultados. $\mathrm{O}$ artigo também procura demonstrar como a extensão universitária influenciou positivamente o projeto final alcançado, bem como no seu processo de criação através de contatos estabelecidos com a comunidade em questão e análises relacionadas ao público-alvo, público usuário e condicionantes físicos do ambiente a ser projetado.

Entende-se que a biblioteca escolar é um espaço de aprendizado e que influencia diretamente no interesse de leitura dos alunos, consistindo em um ambiente de uso comum, amplamente utilizado para estudo, descanso e atividades institucionais. Os resultados positivos comunicados na proposta final podem dar diretrizes para intervenção em outras bibliotecas escolares, buscando tornar esses ambientes mais atrativos e agradáveis a quem os frequenta. 


\section{REFERENCIAL TEÓRICO}

As atividades extensionistas sempre estiveram presentes na rotina dos cursos de Arquitetura e Urbanismo e Design da Universidade Franciscana, mesmo antes da implementação de sua curricularização, em projetos externos às disciplinas. Na revisão das matrizes curriculares dos dois cursos em 2019, a criação de disciplinas em que a extensão passou a fazer parte da obrigatoriedade de suas competências exigiu que professores e alunos repensassem suas práticas e qualificassem seus processos de ensino e aprendizagem.

Para o ForExt (2017, p. 02), a extensão universitária supera as "filosofias educacionais meramente conteudistas", incrementando a formação técnica com responsabilidade social e reconhecendo os saberes externos do ambiente acadêmico. Dos desafios que a extensão impõe na formação universitária, a extensão ganha espaço ao ser reconhecida como ferramenta eficaz para aproximar o "conhecer" do "viver".

Na disciplina de Projeto Comunitário, a presença do componente extensionista modificou a metodologia de projeto tradicional que até então acontecia nas disciplinas práticas, somando a figura de um "cliente" real a quem a proposta de projeto deveria responder. No caso de edição de 2019, o ambiente escolar tornou-se o tema de debate nos projetos, exigindo que os acadêmicos se aproximassem dos elementos que compõem o espaço de ensino e tivessem com clareza os critérios de qualidade que deveriam ser considerados.

De acordo com Kowaltowski (2011), dois grandes fatores influenciam na qualidade do ambiente escolar: os recursos humanos que o compõem e os aspectos organizacionais do espaço. Ainda que no âmbito de Projeto Comunitário não seja possível alterar as pessoas que fazem a escola acontecer no seu cotidiano, defende-se que há características do espaço construído que podem modificar o comportamento dos usuários e sua relação com o meio.

Nesse sentido, leva-se em consideração que aspectos da Psicologia Ambiental ${ }^{5}$ e Neuroarquitetura $^{6}$ devem ser contemplados na etapa de proposição de projeto, respeitando especificidades culturais e faixa etária do público a ser atendido. Independentemente de quais respostas o ambiente é capaz de nos dar, "deve existir a certeza de que o ambiente físico contribui positivamente para criar o contexto adequado, confortável e estimulante para uma produção acadêmica expressiva" (KOWALTOWSKI, 2011, p.40).

A biblioteca, enquanto componente dos espaços de uma escola, trata-se de um recurso pedagógico que contribui para o bom desempenho dos alunos (SILVEIRA, 1996). Historicamente reconhecida como um aglomerado de livros, atualmente assume características de espaço dinâmico, local de leitura e também de lazer, que deve estar conectada com os anseios do público escolar.

\footnotetext{
5 Psicologia Ambiental refere-se ao estudo do comportamento humana em relação com as características do meio.
} 6 Neuroarquitetura refere-se ao estudo das influências do meio ambiente no cérebro. 
Entre as funções da biblioteca escolar, é possível destacar que se trata de espaço formal para aprofundar conhecimentos, devendo configurar-se em um ambiente que promova a formação e desenvolvimento dos hábitos de leitura e pesquisa. O ambiente da biblioteca assume, assim, o papel de mediador entre conteúdos e práticas pedagógicas com os sujeitos que fazem e usufruem da escola (KOWALTOWSKI, 2011).

Para amparar os aspectos de levantamento do espaço escolar e reconhecimento de sua realidade, consolidando os estudos sobre as relações entre pessoas e ambiente, exploram-se metodologias aplicadas de avaliação de desempenho do ambiente construído. Toma-se como base o livro Observando a Qualidade do Lugar: procedimentos para avalição pós ocupação (FAU UFRJ/2009). Esse tem o intuito de sistematizar ferramentas para um melhor entendimento do local, mencionando oito instrumentos pré-estabelecidos que podem ser usados a fim de compreender as relações de ocupação do ambiente, citando-se: walkthrough, mapa comportamental, poema dos desejos, mapeamento visual, mapa mental, seleção visual, entrevista e questionário.

Os métodos de avaliação de pós ocupação auxiliam com padrões de análise, trazendo critérios determinados para comparar com aquilo que está sendo avaliado. Tais ferramentas, quando aplicadas antes e durante o processo projetual, contribuem para reduzir erros e atingir propostas de maior qualidade, conectada às normativas legais de ocupação do espaço e sensíveis à qualidade ambiental desejada por seus usuários.

\section{METODOLOGIA}

Neste texto explora-se a metodologia de projeto adotado para a realização do projeto de interiores da biblioteca da escola, trata-se, portanto, de uma pesquisa qualitativa que demonstra as etapas de trabalho e suas relações até chegar-se ao produto final.

Quanto às etapas de trabalho, é possível organizar as atividades de acordo com o reconhecimento do lugar, a realização de levantamento físico, a apreensão das necessidades e potencialidades do ambiente de projeto, do reconhecimento das preferências dos usuários, e por último, a proposta de qualificação do espaço.

O reconhecimento da escola começou com uma visita ao ambiente de projeto, seguido da realização do levantamento físico e fotográfico do mesmo. Além da coleta de dados, experimentar o espaço como ele se encontra é uma ferramenta valiosa para o projetista identificar aspectos sensoriais como a presença e a efetividade da iluminação natural, correntes de vento, visuais, além de condições de uso do mobiliário existente e da forma de como esse está organizado. O contato com a comunidade aconteceu através de uma conversa com alguns professores, os quais compartilharam suas percepções a respeito da biblioteca e da rotina de uso da mesma, ajudando na leitura do espaço e na identificação de demandas. 
Em outra oportunidade, realizou-se uma oficina didática de interação com os alunos do $9^{\circ}$ ano do Ensino Fundamental da Escola Básica Estadual Cícero Barreto para que fossem coletadas informações e trocadas experiências entre os acadêmicos e os alunos. Tratou-se de uma estratégia de buscar a opinião dos discentes de maneira descontraída e espontânea, em uma atividade que explorou a criatividade e permitiu que esses comunicassem suas ideias e visões do lugar, sendo esse um método de um melhor conhecimento da comunidade.

A oficina consistia na elaboração de cartazes pelos alunos através da técnica da colagem, da criação de desenhos e textos que demonstrassem os seus desejos e expectativas em relação ao futuro projeto da biblioteca (Figura 1). Durante esse processo ocorreu uma conversa visando conhecer os alunos, bem como a realização de perguntas pré-estabelecidas. Também foram distribuídas imagens de bibliotecas e móveis para serem usados como referência e ajudarem os alunos a terem ideias de suas preferências, facilitando seus processos criativos.

Figura 1 - Registros do processo e um exemplo de resultado da oficina.
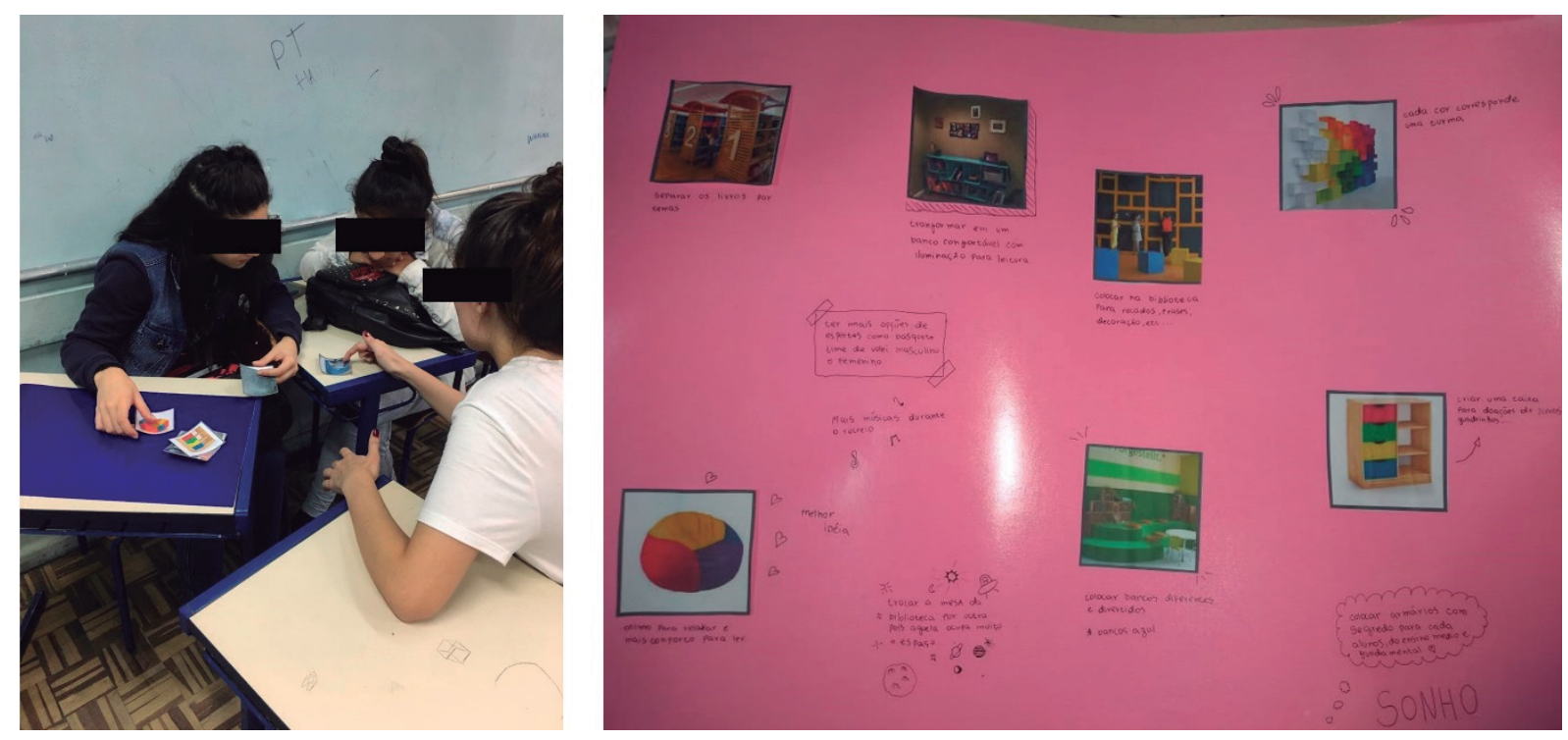

Fonte: Acervo dos autores, 2019.

Após o processo de criação, a proposta final foi representada de maneira didática, com o objetivo de informar aspectos visuais estéticos, e de forma técnica, para fins de execução profissional. O material incluía planta de zoneamento, planta baixa técnica, lista de mobiliário e equipamentos novos necessários, além de planta baixa construir/demolir, planta luminotécnica, planta elétrica e os detalhamentos de mobiliário. Através de uma prancha conceito, de uma planta baixa humanizada e de imagens realistas adequou-se a linguagem técnica do projeto visando comunicá-lo melhor à comunidade, mostrando a materialidade escolhida, as cores, texturas e a disposição do mobiliário de forma fiel à ideia sugerida. 


\section{RESULTADOS}

Bibliotecas são ambientes escolares que incentivam o hábito de leitura tanto na vida pessoal, como um lazer, quanto no processo de aprendizagem e na busca de conhecimento dos estudantes. A biblioteca da Escola Básica Estadual Cícero Barreto encontrava-se em condições precárias, com o piso degradado, esquadrias enferrujadas e pouca iluminação e ventilação natural, sendo pertinente uma intervenção arquitetônica no local devido seu grande potencial. Perucchi e Valmira (1999) destacam que é preciso que os meios usados para educar sejam compatíveis e eficazes, ou seja, utilizar a biblioteca como recurso educativo é fundamental para o desenvolvimento do processo de aprendizagem e formação do educador e do educando.

As discussões realizadas no âmbito de Projeto Comunitário e as análises de todos os grupos da disciplina foram fundamentais para o entendimento das necessidades dos alunos e professores da escola, possibilitando que o projeto fosse satisfatório e de acordo com as expectativas. Assim, estabeleceu-se um diagnóstico da situação física da biblioteca especificamente, selecionando quais elementos eram necessários e os materializando na nova proposta de projeto. Essa concretização decorreu-se da confecção de objetos de estudo que auxiliassem no desenvolvimento do exercício, como a elaboração de painéis semânticos.

A partir do diagnóstico e do conhecimento dos desejos dos alunos, estabeleceram-se duas diretrizes principais: a setorização do espaço e o reaproveitamento do mobiliário existente. A decisão de setorizar o ambiente decorreu-se ao perceber que a biblioteca recebe público de diversas faixas etárias, como crianças, adolescentes, adultos e idosos, ou seja, era preciso acolhê-los de forma confortável e igualitária, respeitando suas limitações e particularidades. A decisão de reaproveitar o mobiliário existente (Figura 2) teve como objetivo tornar o projeto de interiores mais acessível caso executado, fazendo com que os móveis atuais fossem reaproveitados qualificando-os esteticamente.

Figura 2 - Condição existente da biblioteca.
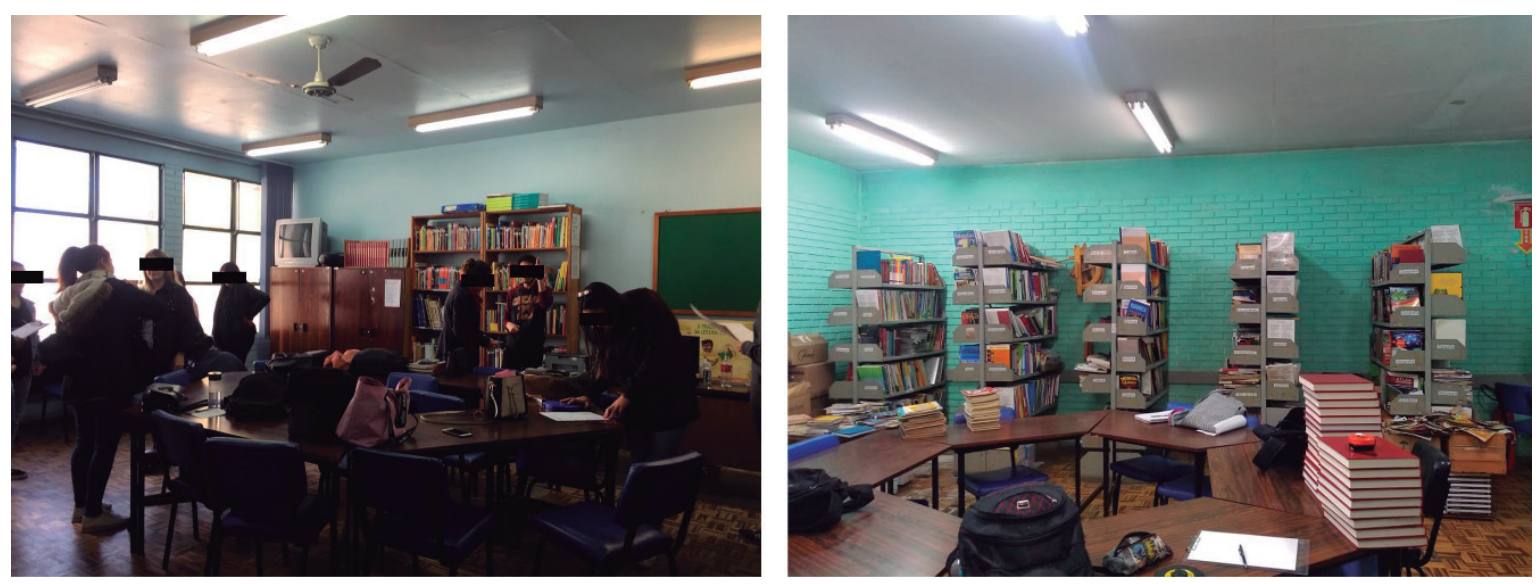

Fonte: Acervo dos autores, 2019. 
A definição dos elementos estéticos da biblioteca sucedeu-se com a elaboração de um painel semântico, exemplificado em parte na Figura 3 e na Figura 4. Esse recurso facilitou a visualização das cores, texturas, revestimentos e demais aspectos escolhidos de maneira conjunta. A escolha das cores foi resultante da análise psicológica sobre o que cada cor transmite para o ambiente e para os seus usuários, visando escolher tons que garantissem harmonia, sensações agradáveis e que não causassem desconforto aos alunos. Também, consideraram-se cores que combinassem com as texturas já existentes que seriam restauradas, como o mobiliário em madeira e o piso em taco de madeira já presente no local. Sendo assim, optou-se por cores em tons amenos, como branco, cinza claro, amarelo e azul em tons pastéis.

Figura 3 - Painel semântico 01: cores e público alvo.

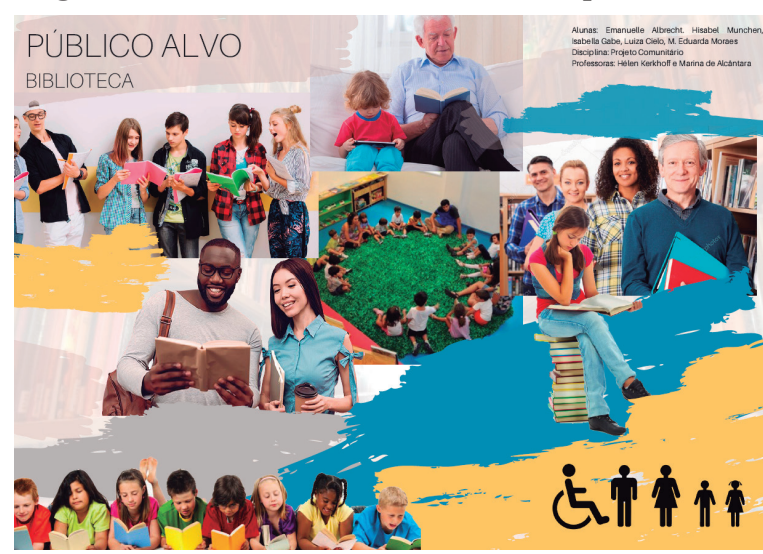

Autor: Acervo dos autores, 2019.
Figura 4 - Painel semântico 02: referências.

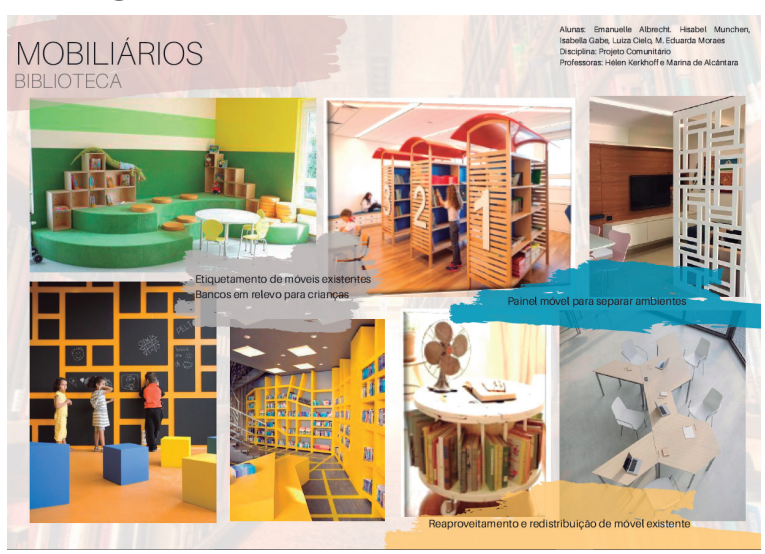

Autor: Acervo dos autores, 2019.

A biblioteca original era composta por duas salas contíguas que separava o espaço em dois ambientes distintos (Figura 5). Essa divisão foi modificada através da retirada de uma parede de alvenaria e pela realocação da porta de acesso (Figura 6). Foi possível criar um ambiente amplo e funcional, garantindo um melhor espaço de permanência, descanso e estudo. Com o espaço já definido foi feita a setorização propriamente dita.

Zoneou-se a sala conforme o pré-dimensionamento dos objetos existentes, visto que as suas quantidades interferem diretamente no espaço utilizado pelos mesmos. Além disso, buscou-se garantir um fluxo de circulação eficiente, o qual permitisse que qualquer setor fosse acessado sem conflitos e com facilidade, sendo essa uma das principais diretrizes da setorização final. Por fim, separou-se a sala em setor infantil, setor administrativo, setor de livros e setor de estudo. Conforme Motta (1999, p. 21), “[...] dentro de uma instituição deve estar bem definida quanto à sua organização e funcionamento para que venha facilitar o ensino e a aprendizagem". 
Figura 5 - Planta baixa original com espaço compartimentado.

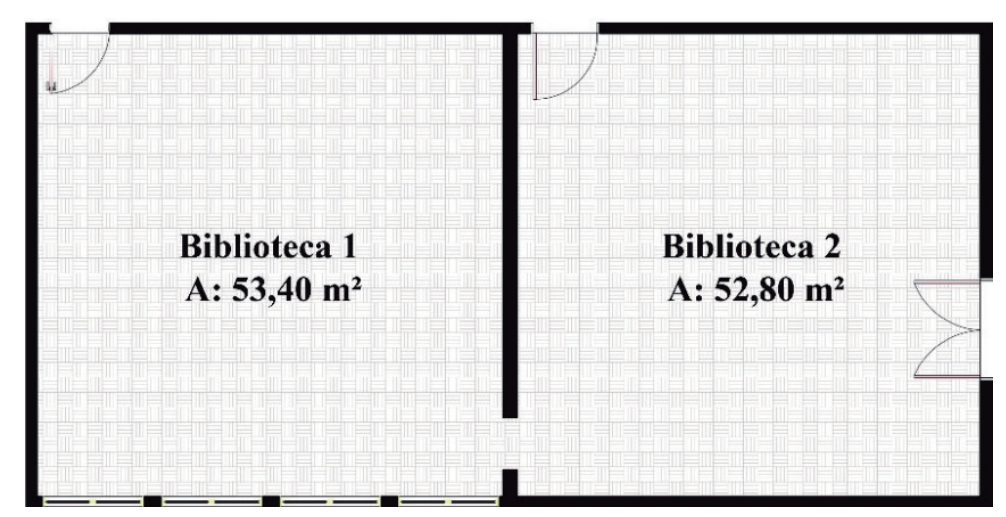

Fonte: Acervo dos autores, 2019.

Figura 6 - Nova proposta de setorização sem a parede divisória interna.

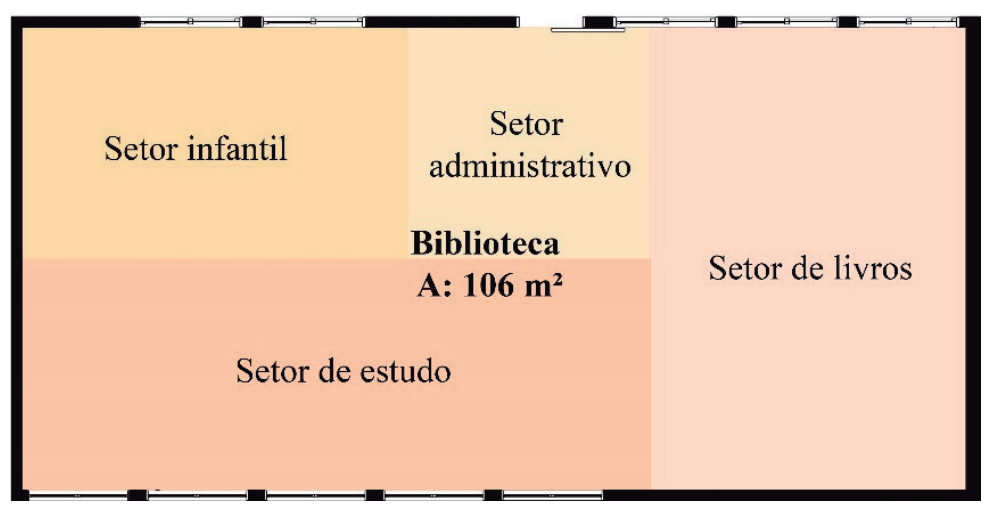

Fonte: Acervo dos autores, 2019.

O setor administrativo, atualmente improvisado, foi localizado junto à porta de entrada, posição estrategicamente pensada para que a secretária tenha um bom campo de visão para o controle de toda sala, conforme Figura 7. Esse é o setor onde ocorre o registro de entrada e saída de materiais e livros, além de também ser o local de armazenamento de equipamentos digitais, como projetor. Próximo às janelas está o setor de estudo, pensado para os estudantes de maior idade e para atividades em grupo.

Devido as aberturas, a iluminação natural abrange a área de mesas e bancada alta central, possibilitando economia em iluminação artificial. Mantiveram-se as cadeiras originais, as quais foram renovadas com um novo estofado preto e adicionaram-se pufes azuis para que esse espaço também seja um local de descanso, havendo a opção de relaxar no intervalo. Quando aberta durante o período da noite, a biblioteca é iluminada por lâmpadas tubulares e pendentes. 
Figura 7 - Planta perspectivada humanizada da proposta.

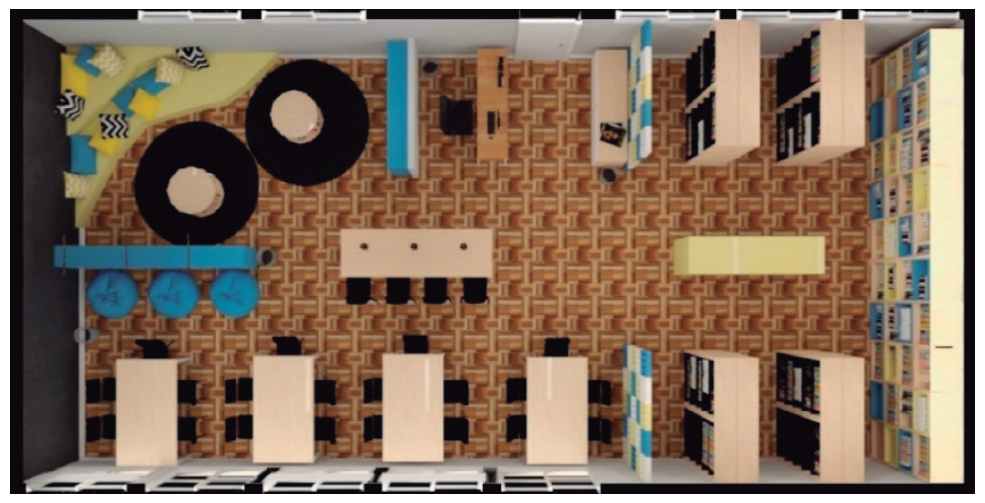

Fonte: Acervo dos autores, 2019.

O setor infantil está posicionado em uma das extremidades da sala, sendo composto por um banco amarelo que pode servir como um pequeno palco, o qual torna o espaço em uma espécie de teatro, servindo para apresentações e rodas de leitura, ou até mesmo para descanso, como desejado pelos estudantes. Houve a reforma das prateleiras baixas existentes, pois elas possuem altura adequada para o acesso das crianças menores e estava em boas condições, de forma que essas foram recobertas com placas de MDF de cor azul. Além disso, colocou-se uma parede lousa para a criação de desenhos, anotações e recados gerais, tornando o espaço lúdico e mais divertido para os alunos (Figura 8). Para o reaproveitamento de elementos, houve a conservação do piso de taco de madeira original, que sofreu requalificação. As aberturas foram mantidas e pintadas na cor branca.

O setor de livros abrange uma grande parte da sala, afinal, esse setor foi uma prioridade projetual devido a intenção de aumentar a quantidade de prateleiras existentes para um maior acervo de livros. Para isso, foram posicionados dois painéis de cobogós nas tonalidades branca, azul e amarelo para delimitar a área de retirada de livros e para que também houvesse permeabilidade visual. As prateleiras existentes foram reaproveitadas e recobertas com MDF em textura natural. A prateleira painel localizada na parede ao fundo faz o fechamento do setor, essa foi pensada para servir como um painel dinâmico, pois possui nichos com tonalidades intercaladas entre azul, amarelo e textura natural do MDF.

Figura 8 - Imagem do projeto.
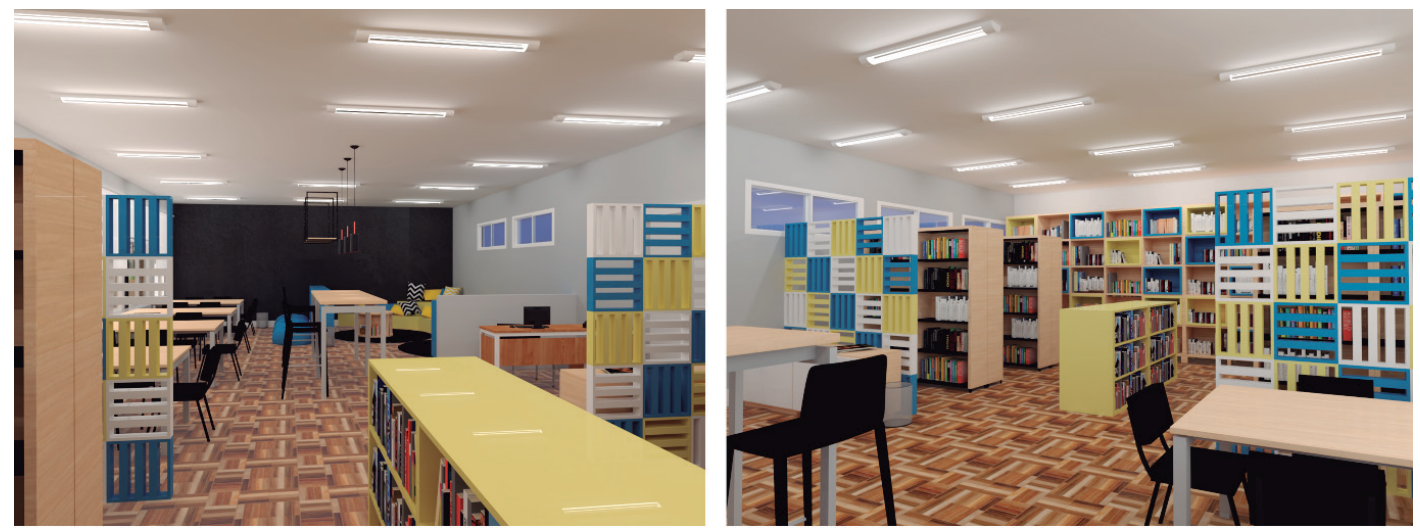

Autor: Acervo dos autores, 2019. 


\section{CONSIDERAÇÕES FINAIS}

Considera-se que com o exercício acadêmica da disciplina de Projeto Comunitário foi possível ampliar as experiências e vivências pessoais dos alunos da UFN com a comunidade externa local, vendo a aplicabilidade da extensão como componente do aprendizado. Além de qualificar as habilidades humanas na formação dos acadêmicos, conforme destaca Souza (2000) a extensão é um instrumento fundamental para que a pesquisa e o ensino sejam executados de maneira útil na sociedade, além da Universidade não participar somente da formação técnica, mas também da construção humana do cidadão.

Com o projeto de interiores da biblioteca da Escola Básica Estadual Cícero Barreto finalizado, pode-se reafirmar que a ideia de uma requalificação dos espaços é uma forma de tornar o estudo, a convivência e as relações interpessoais na escola mais agradáveis, garantindo melhor qualidade de vida no ambiente escolar. Acredita-se que o projeto alcançou um resultado positivo, pois foi possível, juntamente com a participação da comunidade, criar um ambiente que acolhe e traz conforto aos estudantes através da escolha dos elementos, como cores e mobiliário. Além de proporcionar diversos atrativos, como um ambiente de descanso e de criatividade, fazendo com que eles se sintam pertencentes ao espaço.

A disciplina extensionista em seu conceito demonstra que o contato com a comunidade é fundamental tanto no início do processo criativo quanto no final. No caso da disciplina de Projeto Comunitário de 2019 da Universidade Franciscana, o projeto de interiores realizado não pode ser entregue à comunidade, diferentemente do que era a ideia inicial, que seria compartilhar o resultado aos alunos e professores presencialmente. Isso aconteceu devido a influência de fatores externos, como a greve das escolas públicas ocorridas no final do ano. Com isso, nota-se que existem diversos aspectos que influenciam na efetividade da disciplina extensionista como um todo.

Projetar os interiores de uma biblioteca existente, um ambiente nunca antes trabalhado, foi desafiador. Fez-se necessário entender que esse é um espaço não somente de retirada e devolução de livros, mas também um local de incentivo à leitura e à educação. Ou seja, tornar a biblioteca agradável e atrativa é uma maneira de estimular o progresso intelectual e pessoal dos estudantes. Conforme Silveira (1996), os livros disponíveis na biblioteca escolar devem despertar interesse nos estudantes através de seus assuntos, sejam eles relacionados aos seus hábitos, idades e contextos socioculturais. Junto disso, acredita-se que ambientes bem planejados, iluminados e pensados para quem ali convive podem mudar a relação das pessoas com o espaço e suas rotinas.

Desse modo, a disciplina extensionista reafirmou que a troca de ideias com o público é essencial. Presenciar a realidade e não apenas realizar pesquisas dentro do ambiente universitário fez com que os discentes presenciassem os desafios reais, tornando a disciplina mais interessante e produtiva. Cada contato estabelecido devido à extensão durante a etapa de reconhecimento, a aplicação da 
oficina e as entrevistas fizeram com que o processo de criação se tornasse mais gratificante, além de atender com êxito a demanda dos alunos, melhorando suas qualidades de vida e, principalmente, seus processos de aprendizado.

A extensão articula um processo educativo, cultural e científico, ao lado do ensino e da pesquisa, gerado pelas possibilidades e pela força articuladora que está na natureza das ações nascidas das relações sociais e comunitárias. (GARCIA; OLIVEIRA, 2009)

A complementação de conhecimento entre as formações do Arquiteto e do Designer na disciplina foi outro fator fundamental para o desempenho do processo projetual, pois aprofundou os conhecimentos do ponto de vista técnico, ampliando a visualização de novos detalhes do espaço e aprimorando a forma de projetar. Com isso, qualificou-se a compreensão das habilidades complementares entre arquitetos e designers em relação a atribuição legal e responsabilidade técnica de ambos, ampliando as experiências e os conhecimentos adquiridos no período em estudo.

A disciplina de Projeto Comunitário também colaborou com a desconstrução da ideia de que Arquitetura e Design são áreas que atendem somente públicos elitizados, essas também servem em prol da comunidade independentemente do poder aquisitivo ou classe social. A oportunidade de projetar uma biblioteca diretamente com a comunidade usuária em uma escola que, assim como a maioria das escolas no Brasil, não apresenta as melhores condições possíveis, foi uma grande oportunidade. Foi possível ampliar as vivências humanas e relações sociais dentro do ambiente acadêmico e escolar, corroborando para o entendimento das particularidades existentes em cada projeto de interiores.

\section{REFERÊNCIAS}

BRASIL. Lei n.13.005, de 25 de junho de 2014. Aprova o Plano Nacional de Educação - PNE e dá outras providências. Diário Oficial da União, Brasília, DF., 26 jun 2014. Disponível em: https://bit.ly/ 2USJ5p7. Acesso em: 06 abr.2021.

BRASILEIRO, Alice; DE ALCANTARA, Denise; AZEVEDO, Giselle Arteiro; QUEIROZ, Mônica; RHEINGANTZ, Paulo Afonso. Observando a Qualidade do Lugar: procedimentos para a avaliação pós-ocupação. Rio de Janeiro, RJ. PROARQ FAU/UFRJ, 2009.

\section{CARBONARI, Maria; PEREIRA, Adriana. A extensão universitária no Brasil, do assistencialismo à} sustentabilidade. São Paulo. Base de dados do Anhanguera. p. 23-28, set. 2007.

FOREXT. Fórum Nacional de Extensão e Ação Comunitária das Instituições Comunitárias de Ensino Superior. Carta de Porto Alegre: Desafios da Extensão frente ao cenário educacional brasileiro. Porto Alegre, 07 nov. 2017. Disponível em: https://bit.ly/3xdX5rT. Acesso em: 24 maio 2021. 
KOWALTOWSKI, Doris C. C. K. Arquitetura Escolar: o projeto do ambiente de ensino. São Paulo: Oficina de Textos, 2011.

MEC/CNE/CES. Resolução No 7, de 18 de dezembro de 2018. Estabelece as Diretrizes para a Extensão na Educação Superior Brasileira. Diário Oficial da União: Seção 1, Brasília, DF, edição 243, página 49. 19 dez. 2018. Disponível em: https://bit.ly/3hnQa8Z. Acesso em: 06 abr. 2021.

MOTTA, Diana da. Biblioteca escolar: orientações básicas para organização e funcionamento. Revista do Professor, Porto Alegre, v. 15, n. 58, p. 21-24, abr./jun. 1999.

OLIVEIRA, Therezinha Maria Novais de; GARCIA, Berenice Rocha Zabbot. A extensão e o seu papel na formação acadêmica. Revista Univali, Itajaí, v. 14, n. 1, p. 111-117, Jun. 2009

PERUCCHI, V. A importância da biblioteca nas escolas públicas municipais de Criciúma Santa Catarina p. 80-97. Revista ACB, v. 4, n. 4, p. 80-97, ago. 2005. Disponível em: https://bit.ly/ 3AgJXUN. Acesso em: 23 set. 2020.

SILVEIRA, Itália M. F. Ensinar a pensar: uma atividade da biblioteca escolar. R. Bibliotecon. \& Comun., Porto Alegre, v. 7, p. 9-30, jan./dez. 1996.

SOUSA, Ana Luiza Lima. A história da extensão universitária. 1. ed. Campinas: Ed. Alínea, 2000. p. 138. 